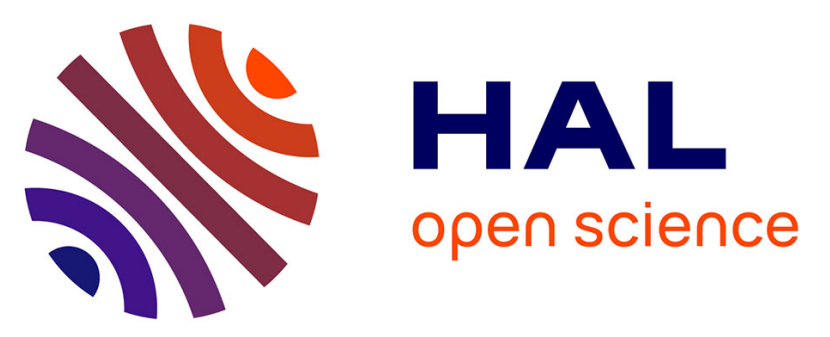

\title{
Elevated Plasma Levels of sRAGE Are Associated With Nonfocal CT-Based Lung Imaging in Patients With ARDS A Prospective Multicenter Study
}

Segolene Mrozek, Matthieu Jabaudon, Samir Jaber, Catherine Paugam-Burtz, Jean-Yves Lefrant, Jean-Jacques Rouby, Karim Asehnoune, Bernard Allaouchiche, Olivier Baldesi, Marc Leone, et al.

\section{To cite this version:}

Segolene Mrozek, Matthieu Jabaudon, Samir Jaber, Catherine Paugam-Burtz, Jean-Yves Lefrant, et al.. Elevated Plasma Levels of sRAGE Are Associated With Nonfocal CT-Based Lung Imaging in Patients With ARDS A Prospective Multicenter Study. Chest, 2016, 150 (5), pp.998-1007. 10.1016/j.chest.2016.03.016 . hal-01453297

\section{HAL Id: hal-01453297 https://hal.science/hal-01453297}

Submitted on 9 Dec 2019

HAL is a multi-disciplinary open access archive for the deposit and dissemination of scientific research documents, whether they are published or not. The documents may come from teaching and research institutions in France or abroad, or from public or private research centers.
L'archive ouverte pluridisciplinaire HAL, est destinée au dépôt et à la diffusion de documents scientifiques de niveau recherche, publiés ou non, émanant des établissements d'enseignement et de recherche français ou étrangers, des laboratoires publics ou privés. 


\title{
Tlevated Plasma Levels of sRAGE Are
} Associated With Nonfocal CT-Based Lung Imaging in Patients With ARDS

\author{
A Prospective Multicenter Study
}

Segolene Mrozek, MD; Matthieu Jabaudon, MD; Samir Jaber, MD, PhD; Catherine Paugam-Burtz, MD, PhD;

Jean-Yves Lefrant, MD, PhD; Jean-Jacques Rouby, MD, PhD; Karim Asehnoune, MD, PhD;

Bernard Allaouchiche, MD, PhD; Olivier Baldesi, MD; Marc Leone, MD, PhD; Qin Lu, MD, PhD;

Jean-Etienne Bazin, MD, PhD; Laurence Roszyk, PharmD; Vincent Sapin, PharmD, PhD; Emmanuel Futier, MD, PhD,

Bruno Pereira, PhD; and Jean-Michel Constantin, MD, PhD; for Azurea network

BACKGROUND: During ARDS, CT can reveal two distinct lung imaging patterns, focal or nonfocal, with different responses to positive end-expiratory pressure, recruitment maneuvers, and prone position. Nevertheless, their association with plasma biomarkers and their distinct functional/pathobiological mechanisms are unknown. The objective of this study was to characterize focal and nonfocal patterns of lung CT-based imaging with plasma markers of lung injury.

METHODS: A prospective multicenter cohort study involving 119 consecutive patients with ARDS. Plasma biomarkers (soluble form of the receptor for advanced glycation end product [sRAGE], plasminogen activator inhibitor-1, soluble intercellular adhesion molecule-1, and surfactant protein-D) were measured within $24 \mathrm{~h}$ of ARDS onset. Lung CT scan was performed within the first $48 \mathrm{~h}$ to assess lung morphology.

RESULTS: Thirty-two (27\%) and 87 (73\%) patients had focal and nonfocal ARDS, respectively. Plasma levels of sRAGE were significantly higher in nonfocal ARDS, compared with focal ARDS. A cut-off of $1,188 \mathrm{pg} / \mathrm{mL}$ differentiated focal from nonfocal ARDS with a sensitivity of $94 \%$ and a specificity of $84 \%$. Nonfocal patterns were associated with higher 28 - and 90 -day mortality than focal patterns ( $31 \%$ vs $12 \%, P=.038$ and $46 \%$ vs $21 \%, P=.026$, respectively). Plasma levels of plasminogen activator inhibitor-1 were significantly higher in nonfocal ARDS. There was no difference in other biomarkers.

CONCLUSIONS: Plasma sRAGE is associated with a nonfocal ARDS. Such novel findings may suggest a role for RAGE pathway in an underlying endotype of impaired alveolar fluid clearance and stimulate future research on the association between ARDS phenotypes and therapeutic responses.

KEY WORDS: alveolar fluid clearance; ARDS phenotype; lung morphology; mechanical ventilation; rage

ABBREVIATIONS: AT = alveolar type; $\mathrm{ES}=$ effect size; $\mathrm{PAI}-1$ = plasminogen activator inhibitor-1; ROC = receiver operating characteristic; SAPS II = simplified acute physiology scores; sRAGE = soluble form of the receptor for advanced glycation end product

AFFILIATIONS: From the Anesthesiology and Critical Care Department (Dr Mrozek), University Hospital of Toulouse, Toulouse, France; Department of Perioperative Medicine (Drs Jabaudon, Bazin, Futier, and
Constantin), University Hospital of Clermont-Ferrand, ClermontFerrand, France; Clermont Université (Drs Jabaudon, Roszyk, Sapin, Futier, and Constantin), Université d'Auvergne, Clermont-Ferrand, France; Department of Anesthesiology and Critical Care Medicine B (Dr Jaber), Saint-Eloi Teaching Hospital, University Hospital of Montpellier, Inserm U-1046, Montpellier, France; Assistance Publique-Hôpitaux de Paris (Dr Paugam-Burtz), Département d'Anesthésie et Réanimation, Hôpital 
ARDS is by definition heterogeneous, encompassing lung injury in the setting of different underlying illnesses. This heterogeneous disease may explain, at least in part, the negative results of large, randomized controlled trials designed to increase survival rate in patients with ARDS. Recent findings from retrospective analyses of large, randomized controlled trials suggest that different ARDS phenotypes (eg, according to inflammatory status or cause of injury) coexist within the syndrome, and are associated with different responses to treatment. ${ }^{1}$

\section{Morphological characterization of CT scan lung}

attenuation has contributed to the recognition of subgroups of patients with ARDS with distinct therapeutic responses (eg, to positive end-expiratory pressure levels)..$^{2-4}$ Nonfocal ARDS, as defined by diffuse lung aeration loss, is usually associated with significant lung recruitability, whereas focal ARDS is characterized by predominant aeration loss in lower lobes and dependent lung regions with low recruitability. Therefore, high positive end-expiratory pressure levels and recruitment

\section{Methods}

We conducted a multicenter, prospective, observational study, after the protocol was approved by the Institutional Review Board the French Ministry of Health (Comité de Protection des Personnes Sud-Est-VI,

Beaujon, Hôpitaux Universitaires Paris Nord Val de Seine and Université Paris Diderot, Sorbonne Paris Cité, France; Service des Réanimations (Dr Lefrant), Pôle Anesthésie Réanimation Douleur Urgence, CHU Nîmes, Faculté de Médecine de Nîmes, Université Montpellier 1, Nîmes, France; Multidisciplinary Intensive Care Unit (Drs Rouby and Lu), Department of Anesthesiology and Critical Care Medicine, Assistance Publique Hôpitaux de Paris, Pitié-Salpêtrière Hospital, University Pierre and Marie Curie of Paris, France; Department of Anesthesiology and Critical Care (Dr Asehnoune), Hotel-Dieu, Nantes, France; Hospices Civils de Lyon Service de Réanimation Médicale Centre Hospitalier Lyon-Sud (Dr Allaouchiche), Pierre Bénite, France; Réanimation (Dr Baldesi), $\mathrm{CH}$ Aix-en-provence, Aix-en-provence, France; Service d'Anesthésie et de Réanimation (Dr Leone), Hôpital Nord, Assistance Publique-Hôpitaux de Marseille, Aix Marseille Université, Marseille, France; Department of Biology (Drs Roszyk and Sapin), University Hospital of Clermont-ferrand, Clermont-ferrand, France; and Biostatistics Unit (Department of Clinical Research and Innovation) (Dr Pereira), University Hospital of Clermont-Ferrand, Clermont-Ferrand, France.

FUNDING/SUPPORT: This work was supported by grants from the Auvergne Regional Council (Programme Nouveau Chercheur de la Region Auvergne 2013), the French Agence Nationale de la Recherche and the Direction Generale de l'Offre de Soins (Programme de Recherche Translationnelle en Sante, ANR-13-PRTS-0010), and Clermont-Ferrand University Hospital (Appel d'Offre Interne 2010, CHU Clermont-Ferrand).

CORRESPONDENCE TO: Jean-Michel Constantin, MD, PhD, Department of Perioperative Medicine, University Hospital of ClermontFerrand, 1 place Lucie Aubrac, 63000 Clermont-Ferrand Cedex, Clermont-Ferrand, France; e-mail: jmconstantin@chu-clermontferrand.fr maneuvers seem more suitable for patients with nonfocal ARDS and may rather generate hyperinflation and hemodynamic instability in patients with focal ARDS. ${ }^{2}$ Despite CT-based lung morphology being useful in identifying distinct subgroups of ARDS, precise functional or pathophysiological mechanisms associated with such CT-based patterns are unknown to date. The soluble form of the receptor for advanced glycation end-products (sRAGE), consisting of the extracellular domain of RAGE, is a marker of lung alveolar type (AT) I cell injury., Recently, our group reported significant differences in plasma sRAGE according to lung morphology assessed by CT scan, with higher levels in patients with nonfocal pattern than in those with focal pattern ${ }^{7}$; however, this monocenter study was not adequately powered to assess such a secondary end point.

We designed the current study to test the hypothesis that focal and nonfocal CT-based lung imaging patterns are associated with distinct profiles of lung injury biomarkers during ARDS.

IDRCB no. 2009-A00880-57/AU810). The trial was registered on clinicaltrials.gov (NCT01161901).

\section{Patients}

Patients were enrolled from June 2010 through June 2011 at 10 ICUs in France. Patients with early ARDS were identified based on the American/European consensus definition within $24 \mathrm{~h}$ of disease onset. Informed written consent was obtained from each patient's next of kin. Patients were excluded if at least one noninclusion criterion was met: age $<18$ years old or pregnancy; acute exacerbation of diabetes, renal replacement therapy for end-stage kidney disease, Alzheimer disease, amyloidosis, metastatic solid neoplasm, hematological malignancies, acute exacerbation of COPD, or chronic liver disease (Child-Pugh C). Such noninclusion criteria were chosen on the basis of previous reports of deregulated RAGE levels in these conditions. ARDS severity was assessed according to the Berlin definition a posteriori, for obvious reasons. ${ }^{8}$

\section{Study Design}

Within the first $24 \mathrm{~h}$ after inclusion, arterial blood samples $(10 \mathrm{~mL})$ were collected from each patient for subsequent biomarker measurements. Lung CT scan was performed within the first $48 \mathrm{~h}$ after inclusion to characterize lung morphology: according to the "CT scan ARDS study group" criteria ${ }^{3,9}$; patients were classified as presenting focal pattern if areas of lung attenuation had a lobar or segmental distribution, or nonfocal pattern if lung attenuations were diffusely distributed throughout the lungs. When CT scan was not feasible (eg, when the patient was too unstable to be transferred outside the ICU), data from frontal chest radiograph examination and lung ultrasound assessment were collected, as previously described ${ }^{10}$ : chest radiographs were classified into focal when hyperattenuated lung areas involved essentially the lower lobes or into nonfocal when hyperattenuated areas were equally disseminated within the upper and lower lobes ${ }^{10}$; and bedside lung ultrasound was used to determine lung morphology (focal or nonfocal aeration loss), as previously reported. ${ }^{11}$

During the first $24 \mathrm{~h}$ after inclusion, demographic characteristics, physiological variables, medications, ventilator settings, and clinical 
and biological data were obtained for all patients. Clinical outcome was recorded until day 90 or discharge from the ICU, whichever occurred first. Intensive care management of patients included in the study was conducted using participating ICUs' standard protocols. The application of currently available guidelines was encouraged.

\section{Study End Points}

The primary end point was the differences in plasma levels of sRAGE between patients with focal and those with nonfocal ARDS phenotypes. Secondary end points included the comparison of focal and nonfocal ARDS phenotype regarding patient outcomes (duration of mechanical ventilation, 28- and 90-day mortality) and levels of different other biomarkers (surfactant protein $\mathrm{D}$, soluble intercellular adhesion molecule-1, and plasminogen activator inhibitor-1 [PAI-1]). In addition, we compared plasma biomarkers between patients with focal and nonfocal ARDS phenotypes and those from a control group (patients under mechanical ventilation but without ARDS; see e-Appendix 1 for criteria).

\section{Statistical Analysis}

Statistical analysis was performed using Stata 13 software (StataCorp LP, College Station, TX). The tests were two-sided, with a type I error set at $\alpha=0.05$. Sample size was fixed according (1) to Cohen's recommendations, ${ }^{12}$ which has defined effect-size (ES) bounds as: small (ES, 0.2), medium (ES, 0.5), and large (ES, 0.8; "grossly perceptible and therefore large") and (2) according to previous work, ${ }^{7}$ we calculated that a sample of 48 patients would allow detecting a difference in plasma sRAGE between focal and nonfocal
ARDS, when considering $\alpha$ and $\beta$ risks of $5 \%$ (bilateral) and $20 \%$. Nevertheless, 300 patients were planned to be included with intermediate analysis each 100 patients. A stop at the first intermediate analysis with significant difference in the primary outcome was a priori decided. Baseline characteristics were presented as mean ( \pm standard deviation) or median [interquartile range] according to statistical distribution (assumption of normality assessed using the Shapiro-Wilk test) for continuous data and as the number of patients and associated percentages for categorical parameters. Comparisons of patient characteristics between the independent groups were performed using the $\chi^{2}$ or Fisher exact tests for categorical variables, and using Student $t$ test or the Mann-Whitney test when appropriate for quantitative parameters (homoscedasticity studied using Fisher-Snedecor's test). Multivariate analysis was conducted by linear and logistic regression models according to the dependent outcome. When suitable, log-transformation was proposed to achieve statistical normal distribution of this outcome. Variables considered in these models were selected if the $P$ value was less than .20 in univariate analysis and according to clinically relevance. ${ }^{13,14}$ Interactions between factors were tested, and the choice of the most parsimonious model was based on information criterion (Akaike and Bayesian) and likelihood ratio. Finally, predictive thresholds were obtained by computing receiver-operating characteristic (ROC) curves and by calculating various indexes (sensibility, Se; specificity, $\mathrm{Sp}$; proportion of correct results; Youden index (Se $+\mathrm{Sp}-1)$; Liu's index, efficiency, likelihood ratio). A sensitivity analysis was carried out to study the attrition bias and to characterize the statistical nature of missing data.

\section{Results}

\section{Baseline Patient Characteristics}

One hundred and nineteen patients with early ARDS were enrolled in the study from June 2010 through June 2011 (e-Fig 1). The first interim analysis was made with data from 100 patients, after the study was stopped for significance for primary end point. Because this was a prospective observational study, the 19 patients subsequently included were maintained. Fifteen patients were included in the control group (e-Appendix 1).

Table 1 summarizes demographic and comorbidity data from patients with ARDS with focal and nonfocal patterns on CT. Reasons for ICU admission were similar between patients with focal and nonfocal ARDS. At baseline, patients with nonfocal CT-based lung imaging had higher simplified acute physiology scores (SAPS II) than those with focal ARDS patterns.

Hemodynamic variables within the first $24 \mathrm{~h}$ were similar between focal and nonfocal ARDS. Eighteen (56\%) patients with focal pattern suffered from septic shock vs $53(62 \%)$ for nonfocal pattern $(P=.065)$. Details on septic status are shown in e-Table 1. Blood lactate levels were $1.6 \pm 1 \mathrm{mmol} / \mathrm{L}$ in patients with focal and $2.5 \pm 2.1 \mathrm{mmol} / \mathrm{L}$ in patients with nonfocal ARDS pattern $(P=.02)$.

\section{Lung CT Scan Classification}

One hundred and three patients underwent lung CT scan examination, and 16 patients had bedside chest radiography and lung ultrasound. Combining results from the CT scans and other lung imaging tools, 32 (27\%) patients had focal ARDS and 87 (73\%) patients had nonfocal CT-based lung imaging ARDS (Fig 1).

\section{ARDS Characteristics}

Causes of lung injury were similar between focal and nonfocal ARDS. Pulmonary infection was the first cause of ARDS in both groups (18 (56\%) and 39 (45\%), respectively, $P=.29$ ). Pulmonary causes were found in 21 patients (66\%) with focal and 64 patients (75\%) with nonfocal ARDS patterns $(P=.30)$. e-Table 2 summarizes baseline respiratory characteristics and ventilator parameters. No difference was found between focal and nonfocal ARDS for respiratory or gas exchange parameters.

\section{Biomarker Measurements}

Plasma levels of sRAGE were significantly higher in nonfocal ARDS $(3,074[1,930-4,404] \mathrm{pg} / \mathrm{mL})$ than in focal ARDS (877 [494-1,049] pg/mL, $P<.001$ ) (Fig 2). Using plasma sRAGE to split focal and nonfocal ARDS, the area under the ROC curve was 0.93 (95\% CI 
[0.86-0.99]) (Fig 3). A cutoff value of $1,188 \mathrm{ng} / \mathrm{mL}$ had sensitivity of $93 \%$ (95\% CI, 85-97), specificity of 84\% (95\% CI, 66-95), positive predictive value of
94\% (95\% CI, 87-98), and negative predictive values of $81 \%$ (95\% CI, 64-93), respectively. After multivariate analysis, only CT-based lung imaging (focal or nonfocal

TABLE 1] Baseline Characteristics of the Patients

\begin{tabular}{|c|c|c|c|}
\hline & Focal ARDS $(n=32)$ & Nonfocal ARDS $(n=87)$ & $P$ \\
\hline Male, No. (\%) & $26(81)$ & $56(64)$ & .17 \\
\hline Age $(y)$, mean \pm SD & $56 \pm 17$ & $57 \pm 17$ & .80 \\
\hline BMI $\left(\mathrm{kg} / \mathrm{m}^{2}\right)$, mean $\pm \mathrm{SD}$ & $27.0 \pm 5$ & $27.3 \pm 9$ & .47 \\
\hline \multicolumn{4}{|l|}{ Previous medical history, No. (\%) } \\
\hline \multicolumn{4}{|l|}{ Cardiovascular } \\
\hline Hypertension & $11(34)$ & $28(32)$ & .30 \\
\hline Coronary disease, MI & $5(16)$ & $11(13)$ & .76 \\
\hline Supraventricular arrhythmia & $5(16)$ & $10(12)$ & .55 \\
\hline Chronic HF & $1(3)$ & $6(7)$ & .67 \\
\hline VTE & $3(9)$ & $6(7)$ & .70 \\
\hline \multicolumn{4}{|l|}{ Respiratory } \\
\hline Tobacco smoking & $15(47)$ & $26(30)$ & .05 \\
\hline Chronic respiratory failure & $2(7)$ & $6(7)$ & 1.00 \\
\hline Asthma & $1(3)$ & $5(6)$ & 1.00 \\
\hline \multicolumn{4}{|l|}{ Neurology } \\
\hline Parkinson disease & $0(0)$ & $4(5)$ & .57 \\
\hline Epilepsy & $2(7)$ & $4(5)$ & .65 \\
\hline Stroke & $2(7)$ & $4(5)$ & .65 \\
\hline \multicolumn{4}{|l|}{ Abdominal } \\
\hline Liver failure & $5(16)$ & $11(13)$ & .67 \\
\hline Inflammatory bowel disease & $0(0)$ & $4(5)$ & .57 \\
\hline \multicolumn{4}{|l|}{ Metabolism } \\
\hline Diabetes (type 1 or 2 ) & $6(19)$ & $16(18)$ & .65 \\
\hline Hypercholesterolemia & $7(22)$ & $11(13)$ & .21 \\
\hline Chronic alcohol use & $10(31)$ & $21(25)$ & .47 \\
\hline Chronic renal failure & $2(7)$ & $9(10)$ & .51 \\
\hline Reasons for admission to ICU, No. (\%) & & & .79 \\
\hline Hemorrhagic shock & $2(6)$ & $2(2)$ & \\
\hline Traumatic brain injury & $0(0)$ & $4(5)$ & \\
\hline Acute renal failure & $0(0)$ & $4(5)$ & \\
\hline Drug intoxication & $0(0)$ & $1(1)$ & \\
\hline Pneumonia & $4(13)$ & $20(23)$ & \\
\hline Aspiration pneumonia & $1(3)$ & $6(7)$ & \\
\hline Multiple trauma & $5(16)$ & $9(10)$ & \\
\hline ARDS & $5(16)$ & $12(14)$ & \\
\hline Severe sepsis & $9(28)$ & $14(16)$ & \\
\hline Postoperative care & $3(9)$ & $6(7)$ & \\
\hline Metabolic disorder & $0(0)$ & $2(2)$ & \\
\hline Other & $3(9)$ & $7(8)$ & \\
\hline SAPS II, mean \pm SD & $46 \pm 21$ & $53 \pm 19$ & .05 \\
\hline SOFA, mean $\pm S D$ & $9 \pm 3$ & $10 \pm 4$ & .18 \\
\hline
\end{tabular}

$\mathrm{HF}=$ heart failure; MI = myocardial infarction; SAPS = simplified acute physiology scores; SOFA = Sepsis-related Organ Failure Assessment. 


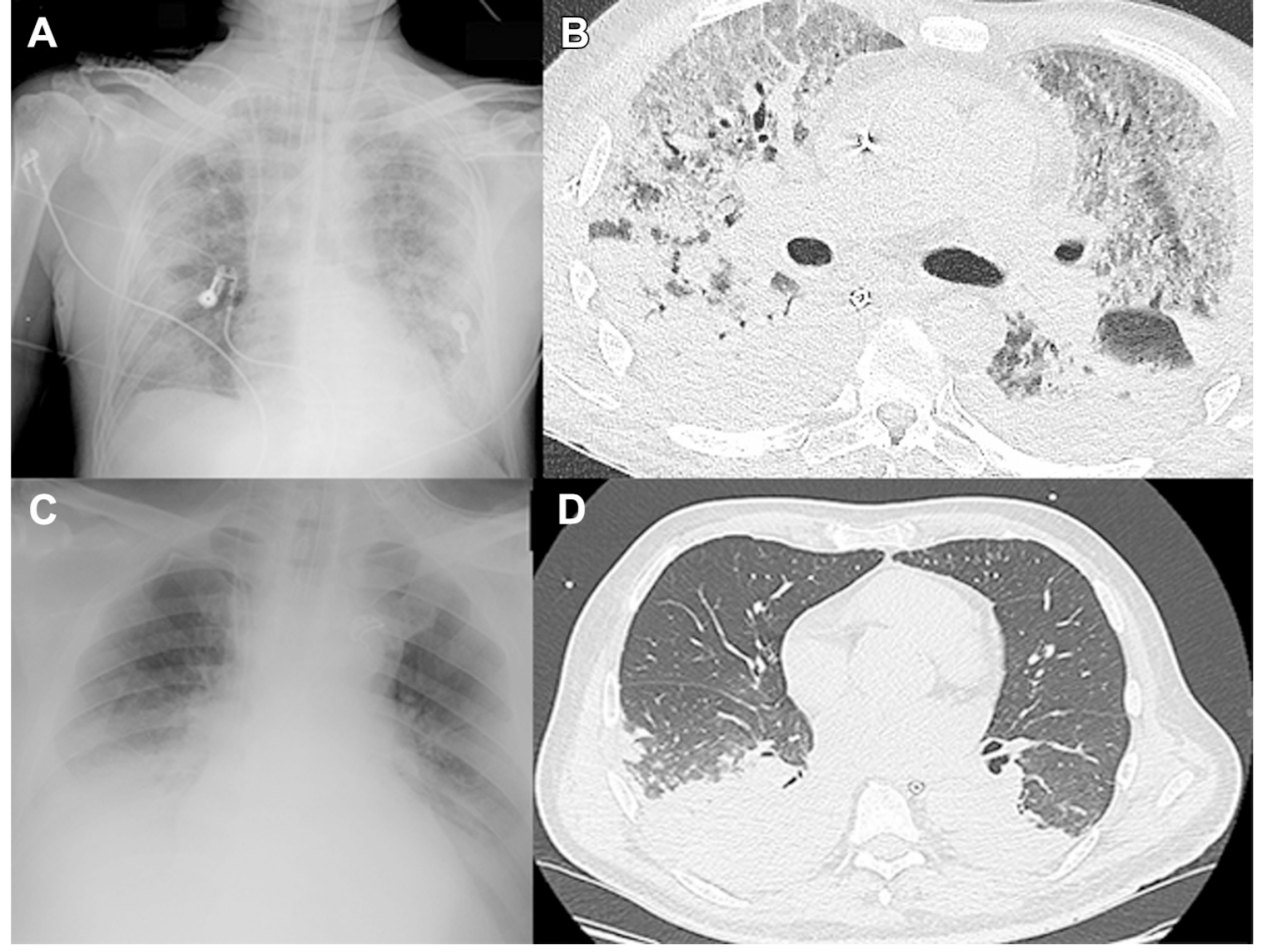

Figure 1 - Bedside chest radiograph and CT scans of two characteristic patients with nonfocal (A, B), and focal (C, D) patterns.

pattern), SAPS II, and plateau pressure were correlated with plasma levels of sRAGE (Table 2). Plasma levels of PAI-1 were higher in nonfocal than in focal ARDS (7.78 [3.13-19.40] ng/mL vs $4.25[2.13-8.16] \mathrm{ng} / \mathrm{mL}$, respectively, $P=.04$ ). Using plasma levels of PAI-1 to split focal and nonfocal ARDS, the area under the ROC curve was 0.63 (95\% CI [0.51-0.74]). In the multivariate analysis, no relevant clinical or biological variable was associated with PAI-1 levels. All plasma levels of biomarkers are reported in e-Table 3.

\section{Outcomes and Mortality}

Duration of ARDS and vasopressor use did not differ between focal and nonfocal CT-based patterns of ARDS. Mortality rates were higher in patients with nonfocal ARDS than in those with focal ARDS at days 28 and 90 (Table 3). In univariate analysis (Table 4), plasma levels of sRAGE were higher in non-survivors $(3,039[1,718$ $4,223] \mathrm{pg} / \mathrm{mL})$ than in survivors $(1,940[972-3,552]$ $\mathrm{pg} / \mathrm{mL}, P=.03)$ up to day 90 . The area under the ROC curve when plasma sRAGE was used to differentiate between survivors and nonsurvivors was $0.61(95 \% \mathrm{CI}$, $0.50-0.71$ ). A cutoff value of $2672 \mathrm{pg} / \mathrm{mL}$ had a sensitivity of $60 \%$ (95\% CI, 43.3-74.4), a specificity of $63 \%$ (95\% CI, 50.7-73.6), a negative predictive value of
$73 \%$ (95\% CI, 60.9-83.7), and a positive predictive value of $47 \%$ (95\% CI, 33.3-61.4). In multivariate analysis, only plasma levels of sRAGE and SAPS II are independent factors of mortality with, respectively, $P=.04$ and $P=.005(\mathrm{OR}=2.9,95 \% \mathrm{CI}, 1.0-7.9$ and $\mathrm{OR}=1.0,95 \% \mathrm{CI}, 1.0-1.1)$.

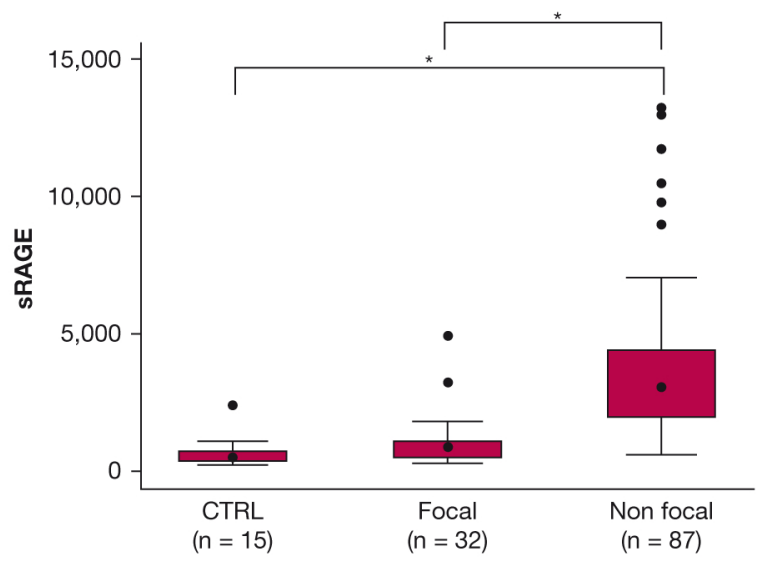

Figure 2 - Box-and-whisker plots of baseline plasma sRAGE levels (in $p g / m L)$ in patients with focal and nonfocal ARDS phenotypes and patients from the control (CTRL) group. Boxes show interquartile ranges, error bars indicate 10th to 90 th percentiles. ${ }^{*} P<.01$. sRAGE $=$ soluble form of the receptor for advanced glycation end product. 


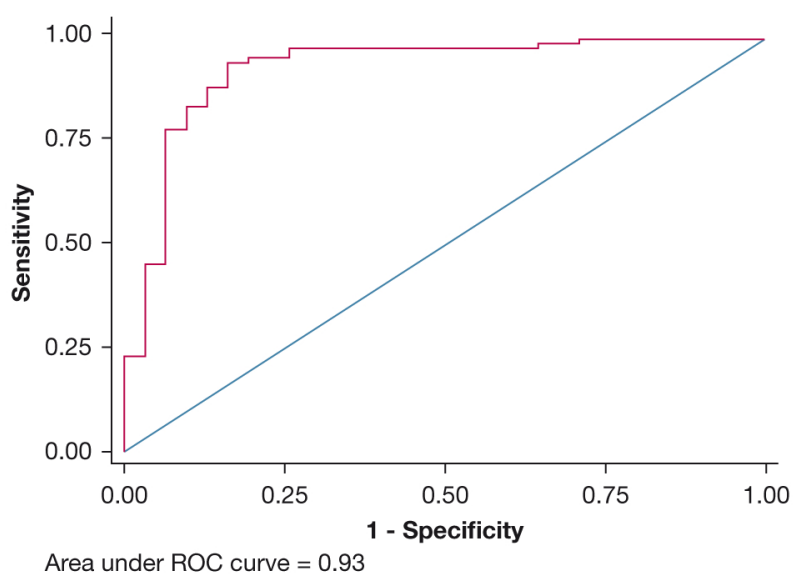

Figure 3 - ROC curve of baseline plasma sRAGE levels (in $\mathrm{pg} / \mathrm{mL}$ ) for differentiating patients with focal ARDS phenotype and those with nonfocal ARDS phenotype. The area under the ROC curve was 0.93 (95\% CI, 0.86-0.99) for a cutoff value of $1,188 \mathrm{pg} / \mathrm{mL}$ with a sensitivity of $94 \%$ and a specificity of $84 \% . R O C=$ received operating characteristic. See Figure 2 legend for expansion of other abbreviation.

\section{Discussion}

In this multicenter observational study, we found that elevated baseline plasma sRAGE is a strong marker of nonfocal CT-based lung imaging pattern in patients with early ARDS.

\section{Biomarkers and Lung Morphology}

Our study is the first to report a strong correlation between lung imaging patterns and plasma sRAGE. Recent animal and human studies support a role for sRAGE as a quantitative biomarker of AT I lung injury, impaired alveolar clearance, and ARDS severity. The higher mortality associated with nonfocal patterns confirms initial reports ${ }^{3}$ and is associated with the alteration of alveolar clearance. ${ }^{20}$ It is in line with the findings reported by Gattinoni et $\mathrm{al}^{21}$ showing a higher mortality in patients with lower proportion of normally aerated lung. Alteration in lung edema resorption is probably a cornerstone in ARDS pathophysiology. ${ }^{22}$ In patients with severe sepsis, plasma levels of sRAGE markedly increase with the presence of ARDS. ${ }^{7}$ sRAGE also has good value for ARDS diagnosis, as evidenced by a recent meta-analysis. ${ }^{23}$ In the present study, plasma levels of sRAGE were higher in nonfocal than in focal ARDS ( $3,074 \mathrm{vs} 877 \mathrm{pg} / \mathrm{mL}$, respectively; $P<.001$ ), thus confirming preliminary data. ${ }^{7}$ An sRAGE cutoff of 1,188 $\mathrm{pg} / \mathrm{mL}$ differentiated focal and nonfocal ARDS phenotypes with high sensitivity (94\%) and specificity (84\%). Whereas focal ARDS is characterized by a decrease in gas volume and moderate inflammatory edema, nonfocal ARDS is associated with significant inflammatory edema and impaired alveolar fluid clearance. Thus, sRAGE represent a reliable marker of diffuse alveolar damage and impaired alveolar fluid clearance during ARDS. ${ }^{7,15,24}$ We therefore hypothesize that lung imaging patterns could be associated with an endotype characterized by impaired alveolar clearance that could be mediated, at least in part, by RAGE pathway. ${ }^{25}$ This hypothesis must be validated by further experimental studies of the effects of RAGE modulation on alveolar clearance. In contrast, markers of AT II cell or endothelial injury (SP-D, sICAM-1, and PAI-1, respectively) did not differ between focal and nonfocal ARDS, suggesting that patterns of CT-based lung morphology may mainly depend on AT I cell injury, a hypothesis being further supported by the major role of AT I cells in the process of alveolar clearance.

\section{Outcomes and Mortality}

In a series of 71 patients with early ARDS studied between 1993 and 1997, patients with nonfocal ARDS had a mortality rate of $66 \%$, whereas those with focal ARDS had a mortality rate of $42 \%{ }^{3}$ In the present study, we confirm in a larger cohort that patients with a nonfocal ARDS have a higher mortality rate than those with focal ARDS ( $46 \%$ vs $21 \%$ at day 90 , respectively; $P=.03)$. The lower absolute mortality rate in the present study may reflect the progress in the management of patients with ARDS during the past few decades. ${ }^{26}$

Recently, Calfee et al ${ }^{1}$ subdivided ARDS into two phenotypes with distinct outcomes. As compared with the ARDS phenotype 1, the ARDS phenotype 2 was characterized by a higher degree of systemic inflammation and higher mortality rates $(44 \%$ vs $23 \%$, $P=.006)$. Such mortality rates are very close to those reported in our study. The same group also reported that higher levels of surfactant protein-D, a biomarker of AT II injury, characterize direct ARDS. In contrast, higher levels of angiopoietin-2, a biomarker of endothelial injury, and higher levels of pro-inflammatory cytokines IL- 6 and IL-8 better characterized indirect ARDS caused by nonpulmonary sepsis. Mortality rate was higher in patients with indirect ARDS than in those with direct ARDS. IL-6, IL-8, angioprotein-2, sRAGE, and von Willebrand factor antigen were strongly predictive of clinical outcomes in patients ventilated with low tidal volumes. ${ }^{6,27}$ Interestingly, the hyperinflammatory phenotype and nonfocal ARDS share similar features (mortality rate, incidence of sepsis, and expression of specific lung injury biomarkers). 
TABLE 2 ] Univariate and Multivariate Analysis of Factors Associated With sRAGE

\begin{tabular}{|c|c|c|c|c|c|}
\hline \multirow[b]{2}{*}{ Parameters } & \multicolumn{2}{|c|}{ Univariate Analysis } & \multicolumn{3}{|c|}{ Multivariate Analysis } \\
\hline & P & r & $\beta$ & $95 \%$ CI & P \\
\hline Age, y & .27 & -0.16 & & & \\
\hline Sex & .19 & & & & \\
\hline BMI $\left(\mathrm{kg} / \mathrm{m}^{2}\right)$ & .02 & -0.14 & $-1,353$ & $-3,258$ to 552 & .16 \\
\hline SOFA & .07 & 0.06 & -173 & -419 to 74 & .17 \\
\hline SAPS II & .17 & 0.17 & 65 & $10-119$ & .02 \\
\hline \multicolumn{6}{|l|}{ Previous medical history } \\
\hline Hypertension & .90 & & & & \\
\hline Coronary diseases, myocardial infarction & .14 & & & & \\
\hline $\mathrm{HF}$ & .04 & & & & \\
\hline Thromboembolism & .70 & & & & \\
\hline Smoking & .49 & & & & \\
\hline Chronic respiratory failure & .79 & & & & \\
\hline Asthma & .52 & & & & \\
\hline Parkinson disease & .25 & & & & \\
\hline Epilepsy & .20 & & & & \\
\hline Liver failure & .18 & & & & \\
\hline Diabetes (type 1 or 2 ) & .25 & & & & \\
\hline Hypercholesterolemia & .20 & & & & \\
\hline Chronic renal failure & .048 & & & & \\
\hline Estimated GFR (MDRD), $\mathrm{mL} / \mathrm{min} / 1.73 \mathrm{~m}^{2}$ & .72 & -0.14 & & & \\
\hline Sepsis & .15 & & -617 & $-3,341$ to 2,108 & .65 \\
\hline $\mathrm{CRP}, \mathrm{mg} / \mathrm{L}$ & .58 & -0.10 & 4.9 & -2.8 to 12.5 & .21 \\
\hline Tidal volume, $\mathrm{mL} / \mathrm{kg}$ of predicted body weight & .049 & -0.12 & -96 & -907 to 715 & .81 \\
\hline PEEP, $\mathrm{cmH}_{2} \mathrm{O}$ & $<.001$ & 0.09 & -81 & -332 to 171 & .52 \\
\hline $\mathrm{PaO}_{2} / \mathrm{FIO}_{2}$ & $<.001$ & -0.10 & 2.6 & -15.6 to 20.7 & .78 \\
\hline Plateau pressure, $\mathrm{cmH}_{2} \mathrm{O}$ & .03 & 0.20 & 206 & $19-394$ & .03 \\
\hline Maximum level of applied PEEP, $\mathrm{cmH}_{2} \mathrm{O}$ & .82 & 0.05 & & & \\
\hline Etiology of ARDS & .03 & & & & \\
\hline Type of ARDS (pulmonary/extrapulmonary) & 31 & & & & \\
\hline Recruitment maneuvers & .94 & & & & \\
\hline
\end{tabular}

Boldface indicates significant values. CRP $=$ C-reactive protein; GFR $=$ glomerular filtration rate; MDRD = modification of the diet in renal disease; PEEP = positive end-expiratory pressure; SRAGE = soluble form of the receptor for advanced glycation end product. See Table 1 legend for expansion of other abbreviations.

TABLE 3 ] Main Outcomes in Patients With Focal vs Nonfocal Forms of ARDS

\begin{tabular}{l|c|c|c}
\hline & Focal ARDS $(n=32)$ & Nonfocal ARDS $(n=87)$ & $P$ \\
\hline Duration of mechanical ventilation (days), median [IQR] & $10[6-19]$ & $12[6-21]$ & .42 \\
Duration of ARDS (days with $\left.\mathrm{PaO}_{2} / \mathrm{FIO}_{2}<300\right)$, median [IQR] & $4[2-6]$ & $4[2-6.5]$ & .58 \\
Duration of vasopressor support (days), median [IQR] & $4[2-7]$ & $5[3-8]$ & .25 \\
Duration of RRT (days), median [IQR] & $2[1-3]$ & $4.5[1-22.5]$ & .08 \\
ICU length of stay (days), median [IQR] & $16.5[8-33]$ & $19[10-36.5]$ & .76 \\
ICU mortality, No. (\%) & $6(18.7)$ & $32(37.6)$ & .052 \\
Mortality at day 28, No. (\%) & $4(12.5)$ & $27(31.4)$ & .038 \\
Mortality at day 90, No. (\%) & $6(21.4)$ & $35(45.5)$ & .026 \\
Mortality up to day 90, No. (\%) & $6(18.7)$ & $36(41.4)$ & .022 \\
\hline \hline
\end{tabular}


TABLE 4] Univariate and Multivariate Analysis for Mortality Up to Day 90 ( $\mathrm{n}=119)$

\begin{tabular}{|c|c|c|c|c|c|c|}
\hline \multirow[b]{2}{*}{ Parameters } & \multicolumn{3}{|c|}{ Univariate Analysis } & \multicolumn{3}{|c|}{ Multivariate Analysis } \\
\hline & Alive $(n=77)$ & Dead $(n=42)$ & $P$ & OR & $95 \%$ CI & $P$ \\
\hline sRAGE (pg/mL), median [IQR] & $1,940(972-3,552)$ & $3,039(1,718-4,223)$ & .03 & 3.1 & $1.1-8.9$ & .009 \\
\hline Nonfocal phenotype, No. (\%) & $51(66)$ & $36(86)$ & .02 & & & \\
\hline $\begin{array}{l}\text { Berlin definition (severe ARDS), } \\
\text { No. }(\%)\end{array}$ & $30(56)$ & $24(44)$ & .15 & 3.84 & $0.7-21$ & .12 \\
\hline Age $(y)$, mean $\pm S D$ & $54 \pm 17$ & $62 \pm 16$ & .01 & & & \\
\hline Male, No. (\%) & $52(68)$ & $30(71)$ & .66 & & & \\
\hline BMI $\left(\mathrm{kg} / \mathrm{m}^{2}\right)$, mean $\pm \mathrm{SD}$ & $27 \pm 9$ & $27 \pm 7$ & .43 & & & \\
\hline SOFA, mean \pm SD & $9 \pm 3$ & $12 \pm 4$ & $<.001$ & 0.99 & $0.79-1.23$ & .95 \\
\hline SAPS II, mean \pm SD & $44 \pm 16$ & $64 \pm 20$ & $<.001$ & 1.0 & $1.0-1.1$ & .005 \\
\hline \multicolumn{7}{|l|}{$\begin{array}{l}\text { Previous medical history, } \\
\quad \text { No. }(\%)\end{array}$} \\
\hline Hypertension & $23(30)$ & $16(38)$ & .36 & & & \\
\hline Coronaropathy, MI & $8(10)$ & $8(19)$ & .19 & & & \\
\hline Heart failure & $2(3)$ & $5(12)$ & .04 & 1.9 & $0.2-16.2$ & .55 \\
\hline Thromboembolism & $5(7)$ & $4(10)$ & .55 & & & \\
\hline Smoking & $29(38)$ & $12(27)$ & .32 & & & \\
\hline Chronic respiratory failure & $5(6)$ & $3(7)$ & .89 & & & \\
\hline Asthma & $5(6)$ & $1(2)$ & .33 & & & \\
\hline Parkinson disease & $3(4)$ & $1(2)$ & .66 & & & \\
\hline Epilepsy & $3(4)$ & $3(7)$ & .44 & & & \\
\hline Liver failure & $10(13)$ & $6(14)$ & .84 & & & \\
\hline Inflammatory bowel disease & $2(3)$ & $2(5)$ & .54 & & & \\
\hline $\begin{array}{l}\text { Insulin-dependent or non- } \\
\text { insulin-dependent diabetes }\end{array}$ & $8(10)$ & $14(33)$ & .002 & 1.9 & $0.2-19$ & .56 \\
\hline Hypercholesterolemia & $11(14)$ & $7(17)$ & .73 & & & \\
\hline Chronic renal failure & $7(9)$ & $4(10)$ & .94 & & & \\
\hline $\begin{array}{l}\mathrm{MDRD}\left(\mathrm{mL} / \mathrm{min} / 1.73 \mathrm{~m}^{2}\right) \\
\quad \text { mean } \pm \mathrm{SD}\end{array}$ & $81 \pm 52$ & $66 \pm 51$ & .09 & & & \\
\hline $\mathrm{GGT}(\mathrm{UI} / \mathrm{L})$, mean $\pm \mathrm{SD}$ & $130 \pm 147$ & $161 \pm 137$ & .07 & & & \\
\hline Natremia $(\mathrm{mmol} / \mathrm{L})$, mean $\pm \mathrm{SD}$ & $140 \pm 5$ & $143 \pm 7$ & .01 & & & \\
\hline Lactates $(\mathrm{mmol} / \mathrm{L})$, mean $\pm \mathrm{SD}$ & $1.9 \pm 1.4$ & $3.1 \pm 2.5$ & .002 & 1.1 & $0.79-1.5$ & .49 \\
\hline Sepsis, No. (\%) & $63(82)$ & $40(95)$ & .01 & 1.8 & $0.3-11$ & .49 \\
\hline Vasopressor, No. (\%) & $55(71)$ & $38(91)$ & .03 & & & \\
\hline Inotrope, No. (\%) & $8(10)$ & $9(21)$ & .06 & & & \\
\hline $\begin{array}{l}\text { Ideal } \mathrm{Vt}(\mathrm{mL} / \mathrm{kg} \text { of predicted } \\
\text { body weight), mean } \pm \mathrm{SD}\end{array}$ & $6.7 \pm 1.1$ & $6.9 \pm 1.2$ & .21 & & & \\
\hline $\operatorname{PEEP}\left(\mathrm{cmH}_{2} \mathrm{O}\right)$, mean $\pm \mathrm{SD}$ & $10.9 \pm 3$ & $10.6 \pm 4$ & .65 & & & \\
\hline $\mathrm{PaO}_{2} / \mathrm{FiO}_{2}$, mean $\pm \mathrm{SD}$ & $122 \pm 51$ & $103 \pm 55$ & .01 & 1 & $0.99-1.02$ & .42 \\
\hline $\begin{array}{l}\text { Plateau pressure }\left(\mathrm{cmH}_{2} \mathrm{O}\right) \\
\text { mean } \pm \mathrm{SD}\end{array}$ & $26.5 \pm 4.7$ & $27.5 \pm 6.1$ & .45 & & & \\
\hline PEEP max $\left(\mathrm{cmH}_{2} \mathrm{O}\right)$, mean $\pm \mathrm{SD}$ & $13 \pm 3$ & $12 \pm 4$ & .42 & & & \\
\hline $\begin{array}{l}\text { Recruitment maneuvers, } \\
\text { No. }(\%)\end{array}$ & $36(4)$ & $22(5)$ & .52 & & & \\
\hline
\end{tabular}

Boldface indicates significant values. GGT = gamma-glutamyl transpeptidase; vt = tidal volume. See Table 1, 2, and 3 legends for expansion of other abbreviations. 


\section{Study Limitations}

First, sRAGE levels were only measured at baseline (ie, at the early stage of ARDS). We did not report here the evolution of those biomarkers over time, but we previously demonstrated that plasma sRAGE decreases with ARDS resolution. ${ }^{7}$ Second, we only measured plasma sRAGE, because it is likely that the source of RAGE during ARDS is the lung. In a recent study, we reported that plasma and bronchoalveolar lavage RAGE levels were correlated. ${ }^{28}$ Third, the area under the ROC curve for plasma RAGE was only 0.61 for survivors vs nonsurvivors, with a positive predictive value of only $47 \%$, and the usefulness of monitoring levels of sRAGE in patients with ARDS should be assessed in further studies. ${ }^{29}$ Also, lung morphology was not assessed by chest CT scan in $13 \%$ of included patients, but only two of them were classified as focal forms, reflecting a low probability of misclassification. ${ }^{10}$ In our study, ultrasound-based assessment of lung morphology was performed in patients without CT scan. However, this technique was previously reported as reliable and reproducible. ${ }^{30}$ Finally, we found no statistical difference in sRAGE levels between patients with ARDS with focal lung imaging patterns on $\mathrm{CT}$ and control patients without ARDS. A lack of statistical power may explain this absence of difference for such a secondary end point. Fifth, the cutoff found to split focal and nonfocal patients with ARDS is lower in this study than that found in our preliminary study $(1,188 \mathrm{vs} 2,066 \mathrm{pg} / \mathrm{mL}){ }^{7}$ These two cutoffs were statistically defined for the best sensitivity/specificity and the difference could be explained by the sample size and severity. In the future, because these parameters are not intrinsic, the cutoff used should be adapted according to the goal of the test.

\section{In conclusion, plasma sRAGE is a strong biomarker} of CT-based lung imaging patterns in patients with ARDS. These imaging patterns may be explained by an endotype related to impaired alveolar fluid clearance. Because such phenotypes may be associated with mortality and distinct responses to ventilator settings, these results have stimulated an ongoing multicenter randomized controlled study (Live Study), aiming at personalizing ventilator setting according to CT-based lung imaging patterns in ARDS.

\section{Acknowledgments}

Author contributions: J.-M. C. takes responsibility for the content of the manuscript; was involved in the conception, hypotheses delineation, and design of the study; acquisition and analysis of the data; and in writing the article and in its revision prior to submission. S. M., M. J., and E. F. were involved in the design of the study, hypotheses delineation, acquisition and analysis of the data, and in writing the article and in its revision before submission. L. R. and V.S. were involved in the design of the study, performing the biological analysis, and in writing the article and in its revision prior to submission. J.-J. R. and M. L. were involved in the design of the study, acquisition and analysis of the data, and in writing the article and in the revision of this article before submission. B. P. was involved in the hypotheses delineation and design of the study, responsible for statistical analysis, and took part in writing the article and in its revision before submission. S. J., C. P.-B., K. A., O. B., J. Y. L., Q. L. and J.-E. B. were involved in the design of the study, acquisition and analysis of the data, and in the revision of this article before submission.

Financial/nonfinancial disclosures: The authors have reported to CHEST the following: S. J. has received consulting fees from Maquet, Draeger, Hamilton Medical, and Fisher Paykel. C. P.-B. has participated in speaking activities and industry advisory boards for Baxter Gambro Hospal and MSD.
E. F. has received consulting fees from General Electric Medical System and Baxter, lecture fees from Baxter and Fresenius Kaki, and travel reimbursement from Fisher \& Paykel Healthcare. None declared (S. M., M. J., J.-Y. L., J.-J. R., K. A., B. A., O. B.., M. L., Q. L., J.-E. B., L. R., V.S., B. P., J.M. C.).

Role of sponsors: The sponsor had no role in the design of the study, the collection and analysis of the data, or the preparation of the manuscript.

\section{References}

1. Calfee CS, Delucchi K, Parsons PE, et al. Subphenotypes in acute respiratory distress syndrome: latent class analysis of data from two randomised controlled trials. Lancet Respir Med. 2014;2(8):611-620.

2. Constantin JM, Grasso S, Chanques G, et al. Lung morphology predicts response to recruitment maneuver in patients with acute respiratory distress syndrome. Crit Care Med. 2010;38(4):1108-1117.

3. Rouby JJ, Puybasset L, Cluzel P, Richecoeur J, Lu Q, Grenier P. Regional distribution of gas and tissue in acute respiratory distress syndrome. II. Physiological correlations and definition of an ARDS Severity Score. CT Scan ARDS Study Group. Intens Care Med. 2000;26(8):1046-1056.
4. Puybasset L, Gusman P, Muller JC, Cluzel P, Coriat P, Rouby JJ. Regional distribution of gas and tissue in acute respiratory distress syndrome. III. Consequences for the effects of positive end-expiratory pressure. CT Scan ARDS Study Group. Adult Respiratory Distress Syndrome. Intens Care Med. 2000;26(9): 1215-1227.

5. Nakamura T, Sato E, Fujiwara N, Kawagoe Y, Maeda S, Yamagishi S. Increased levels of soluble receptor for advanced glycation end products (sRAGE) and high mobility group box 1 (HMGB1) are associated with death in patients with acute respiratory distress syndrome. Clin Biochem. 2011;44(8-9): 601-604.

6. Calfee CS, Ware LB, Eisner MD, et al. Plasma receptor for advanced glycation end products and clinical outcomes in acute lung injury. Thorax. 2008;63(12): 1083-1089.

7. Jabaudon M, Futier E, Roszyk L, et al. Soluble form of the receptor for advanced glycation end products is a marker of acute lung injury but not of severe sepsis in critically ill patients. Crit Care Med. 2011;39(7):480-488.

8. Ranieri VM, Rubenfeld GD, Thompson BT, et al. Acute respiratory distress syndrome: the Berlin Definition. JAMA. 2012;307(23): 2526-2533.

9. Puybasset L, Cluzel P, Gusman P, Grenier P, Preteux F, Rouby JJ. Regional distribution of gas and tissue in acute 

2007;293(1):L52-L59.

Scan ARDS Study Group. Crit Care Med. 2000;26(7):857-869.

10. Lichtenstein D, Goldstein I, Mourgeon E, Cluzel P, Grenier P, Rouby JJ. Comparative diagnostic performances of auscultation, chest radiography, and lung ultrasonography in acute respiratory distress syndrome. Anesthesiology. 2004;100(1):9-15.

11. Arbelot C, Ferrari F, Bouhemad B, Rouby JJ. Lung ultrasound in acute respiratory distress syndrome and acute lung injury. Curr Opin Crit Care. 2008;14(1):70-74.

12. Cohen J. Statistical Power Analysis for the Behavioral Sciences. 2nd ed. Mahwah, NJ: Lawrence Erlbaum; 1988.

13. Harrell FE Jr., Lee KL, Mark DB. Multivariable prognostic models: issues in developing models, evaluating assumptions and adequacy, and measuring and reducing errors. Stat Med. 1996;15(4):361-387.

14. Malek MH, Berger DE, Coburn JW. On the inappropriateness of stepwise regression analysis for model building and testing. Eur J Appl Physiol. 2007;101(2): 263-264; author reply 265-266.

15. Jabaudon M, Blondonnet R, Roszyk L, et al. Soluble RAGE predicts impaired alveolar fluid clearance in acute respiratory distress syndrome. Am J Respir Crit Care Med. 2015;192(2):191-199.

16. Uchida T, Shirasawa M, Ware LB, et al. Receptor for advanced glycation endproducts is a marker of type I cell injury in acute lung injury. Am J Respir Crit Care Med. 2006;173(9):1008-1015.

17. Frank JA, Briot R, Lee JW, Ishizaka A, Uchida T, Matthay MA. Physiological and biochemical markers of alveolar epithelial

18. Briot R, Frank JA, Uchida T, Lee JW, Calfee CS, Matthay MA. Elevated levels of the receptor for advanced glycation end products, a marker of alveolar epithelial type I cell injury, predict impaired alveolar fluid clearance in isolated perfused human lungs. Chest. 2009;135(2):269-275.

19. Guo WA, Knight PR, Raghavendran K. The receptor for advanced glycation end products and acute lung injury/acute respiratory distress syndrome. Crit Care Med. 2012;38(10):1588-1598.

20. Jabaudon M, Blondonnet R, Lutz J, et al. Net alveolar fluid clearance is associated with phenotypes of lung morphology in acute respiratory distress syndrome. Anaesth Crit Care Pain Med. 2016. In press. http://dx.doi.org/10.1016/j.accpm. 2015.11.006.

21. Gattinoni L, Caironi P, Cressoni M, et al. Lung recruitment in patients with the acute respiratory distress syndrome. N Engl J Med. 2006;354(17):1775-1786.

22. Mansel A, Calfee CS. Focusing on the alveolar epithelium: alveolar fluid clearance in diffuse vs focal ARDS. Anaesth Crit Care Pain Med. 2016. In press. http://dx.doi.org/10.1016/j.accpm. 2016.02.003.

23. Terpstra ML, Aman J, van Nieuw Amerongen GP, Groeneveld AB. Plasma biomarkers for acute respiratory distress syndrome: a systematic review and metaanalysis*. Crit Care Med. 2014;42(3): 691-700.

24. Constantin JM, Cayot-Constantin S, Roszyk L, et al. Response to recruitment clearance in acute respiratory distress syndrome. Anesthesiology. 2007;106(5): 944-951.

25. Downs CA, Kreiner LH, Johnson NM, Brown LA, Helms MN. Receptor for advanced glycation end-products regulates lung fluid balance via protein kinase C-gp91(phox) signaling to epithelial sodium channels. Am J Respir Cell Mol Biol. 2015;52(1):75-87.

26. Sigurdsson MI, Sigvaldason K, Gunnarsson TS, Moller A, Sigurdsson GH. Acute respiratory distress syndrome: nationwide changes in incidence, treatment and mortality over 23 years. Acta Anaesthesiol Scand. 2013;57(1):37-45.

27. Calfee CS, Janz DR, Bernard GR, et al. Distinct molecular phenotypes of direct vs indirect ARDS in single-center and multicenter studies. Chest. 2015;147(6): 1539-1548.

28. Jabaudon M, Blondonnet R, Roszyk L, et al. Soluble Forms and Ligands of the Receptor for Advanced Glycation End-Products in Patients with Acute Respiratory Distress Syndrome: an observational prospective study. PloS One. 2015;10(8):e0135857.

29. Jabaudon M, Hamroun N, Roszyk L, et al. Effects of a recruitment maneuver on plasma levels of soluble RAGE in patients with diffuse acute respiratory distress syndrome: a prospective randomized crossover study. Intens Care Med. 41(5): 846-855.

30. Bouhemad B, Mongodi S, Via G, Rouquette I. Ultrasound for "lung monitoring" of ventilated patients. Anesthesiology. 2015;122(2):437-447. 